
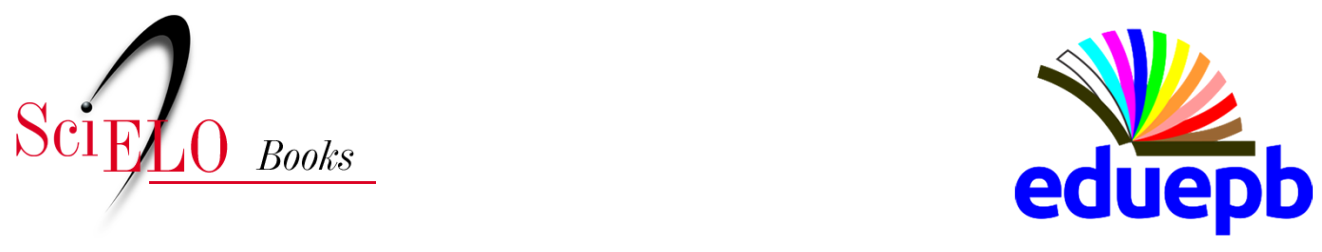

\title{
Aprendendo e fazendo com o Mestre José Maria Aragão - Contra o status quo, Sudene, liberdade e desenvolvimento
}

\author{
Andreza Dantas Albuquerque
}

\section{SciELO Books / SciELO Livros / SciELO Libros}

ALBUQUERQUE, A. D. José Maria Aragão - Contra o status quo, Sudene, liberdade e desenvolvimento. Interviewed: José Maria Aragão. In: SOUSA, C. M., THEIS, I. M., and BARBOSA, J. L. A., eds. Celso Furtado: a esperança militante (Depoimentos): vol. 2 [online]. Campina Grande: EDUEPB, 2020, pp. 141-166. Projeto editorial 100 anos de Celso Furtado collection. ISBN: 978-65-86221-11-4. https://doi.org/10.7476/9786586221671.0005.

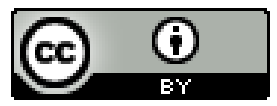

All the contents of this work, except where otherwise noted, is licensed under a Creative Commons Attribution 4.0 International license.

Todo o conteúdo deste trabalho, exceto quando houver ressalva, é publicado sob a licença Creative Commons Atribição 4.0.

Todo el contenido de esta obra, excepto donde se indique lo contrario, está bajo licencia de la licencia Creative Commons Reconocimento 4.0. 


\section{José Maria Aragão*}

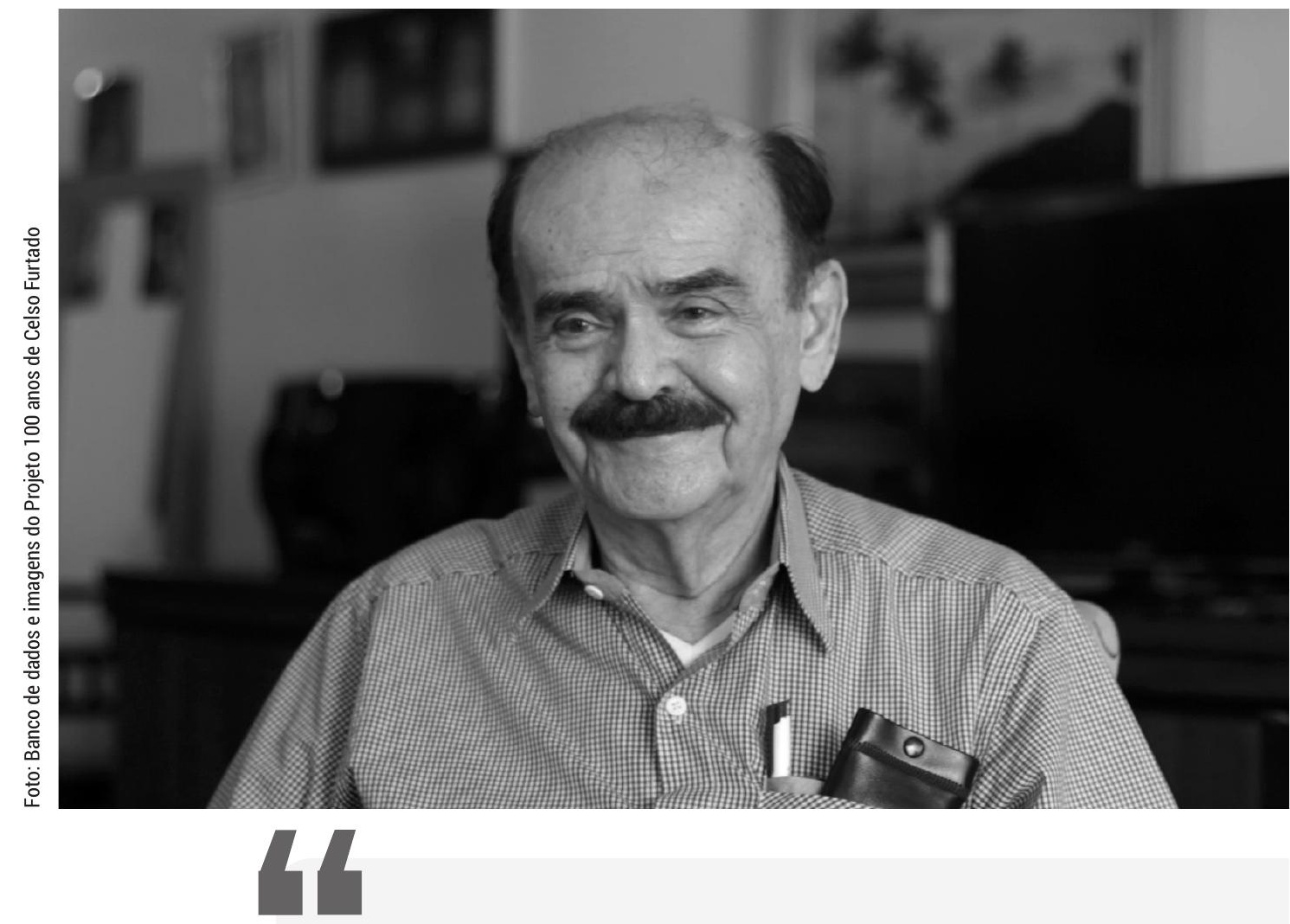

Uma instituição para o planejamento regional sempre tem um papel importante a desempenhar aqui no Nordeste, um deles é o de reforçar os pleitos da região, conferindo uma dimensão regional a projetos que podem ter origem estadual, mas que podem ter uma repercussão regional, nesse sentido um organismo de planejamento regional sempre será de utilidade. Agora, evidente que as prioridades hoje teriam de ser diferentes, daqueles que estiverem presentes no momento da fundação da Sudene.

* Entrevista realizada em 05/04/2017 no contexto das atividades do Procondel (Sudene - UFPE), por Angela Nascimento, mestre em Ciência da Informação, e cedida aos organizadores da Trilogia: Celso Furtado: a esperança militante. 


\section{Contra o status quo, Sudene, liberdade e desenvolvimento}

Wascido em Vitoria de Santo Antão, o pernambucano José Maria nica e administrativa em diversos órgãos públicos no Brasil e agências internacionais, como a Comissão Econômica para a América Latina (Cepal) e o Banco Interamericano de Desenvolvimento (BID), chegou à Superintendência do Desenvolvimento do Nordeste (Sudene), em 1959, atendendo, como ele faz questão de dizer, a um "chamamento" de Celso Furtado.

Aragão, funcionário do Banco do Brasil desde 1952, morava no Rio de Janeiro, quando aceitou o "chamamento" e assumiu o escritório da Sudene no Estado. No período em que esteve na Sudene, desempenhou as funções de assessor do superintendente para análise de projetos industriais, foi chefe do grupo de comércio exterior, diretor do escritório do Rio, coordenador dos projetos internacionais e diretor da assessoria técnica em Recife.

A trajetória profissional reflete-se, também, na produção intelectual visto seu interesse em abordar o tema da integração nacional. Entre os títulos publicados destacamos: "O Brasil e a integração econômica da América (1969)"; "A Harmonização de políticas Macroeconômicas no MERCOSUL: a construção de um mercado comum (1993)"; e "La esencialidad de una política de competencia para el exito de los objetivos del Mercosur (1995)".

Nesta entrevista, concedida à pesquisadora Angela Nascimento', coordenadora executiva do Procondel (Projeto de Preservação e Disponibilização do acervo do Conselho Deliberativo da Sudene 1959200o), Aragão nos conta como acompanhou de perto os fatos que marcaram o surgimento da Sudene e fala de sua atuação como assessor

1 Graduada em história pela Universidade Estadual de Pernambuco, especialista em arquivologia pelo Ministério de Cultura da Espanha, mestrado em Ciência da Informação pela Universidade Federal de Pernambuco e sócia do Centro Internacional Celso Furtado de Políticas para o Desenvolvimento. 
de Celso Furtado em dois momentos: até 1960 e, dois anos depois, ao regressar de Paris, para a implantação da assessoria técnica da instituição, em Recife (PE), a pedido do próprio Furtado. "A Sudene tinha crescido muito em atividade fim e necessitava melhorar o seu nível de coordenação nas diversas equipes", recorda. Para o economista, antes da Sudene "o dinheiro federal, digamos, atingia um objetivo imediato de mitigar a fome daquelas populações privadas de maneiras de subsistência, mas em nada contribuía para mudar a face da região". A criação da Sudene representou, na época, uma reforma administrativa de grande vulto, porque era a primeira vez que um grupo de governadores se reunia de forma orgânica em um colegiado para discutir, em conjunto, os problemas da região. "Um marco para o Nordeste", assegura.

José Maria Aragão atuou na Sudene até $1^{\circ}$ de abril de 1964 e presenciou os últimos momentos de Celso Furtado à frente da instituição. Desses momentos, destaca o clima de apreensão que tomou conta de todos com a possibilidade da prisão de Furtado. "Circulava a notícia de que ele seria preso a qualquer momento, e ele já tinha uma maletinha pronta com as roupas para levar para a prisão. E algumas instruções sobre quem procurar nesse caso", conta.

Por fim, a entrevistadora o faz refletir sobre o papel da atual Sudene. Na percepção de Aragão, é importante que se tenha no Nordeste uma instituição de planejamento e ação, que confira uma dimensão regional a projetos que, inclusive, podem ter origem no âmbito estadual.

(Andreza Dantas Albuquerque) $^{2}$

\section{Entrevista}

- O senhor podia começar se apresentando, dizendo o seu nome, formação e quando o senhor começou na Sudene.

O meu nome é José Maria Aragão, sou doutor em Direito pela Universidade Federal de Pernambuco, e pós-graduado em Economia pela Universidade de Paris. Fiz os dois cursos básicos aqui em Pernambuco, tanto o de Economia quanto o de Direito. Em março

2 Jornalista, Doutora em Ciência, Tecnologia e Sociedade pala UFSCar, pesquisadora vinculada ao Programa de Pós-graduação em Desenvolvimento Regional da Universidade Estadual da Paraíba na condição de estágio pós-doutorado. 
de 1959 estava trabalhando no Rio de Janeiro, no Banco do Brasil, do qual era funcionário, quando fui sondado por um amigo em comum, meu e do Celso Furtado, sobre o meu interesse em integrar a equipe fundadora da Sudene. Por coincidência o meu discurso de formatura de economista tinha sido baseado em trabalhos de Celso Furtado, um debate que se tornou muito conhecido entre ele e um economista inglês 3 , Ragnar Nurkse, da Universidade de Oxford, e esse debate estava publicado na revista da Fundação Getúlio Vargas, a Revista Brasileira de Economia. Então, baseado nesse debate eu redigi o meu discurso de formatura. O meu primeiro convite para trabalhar com Celso Furtado teve o valor de um chamamento, inclusive eu me orientava para outras outras finalidades: eu pretendia, naquela época, seguir carreira diplomática, por isso fui para o Rio de Janeiro. A oportunidade de trabalhar com ele [Celso Furtado] e integrar a equipe fundadora da Sudene teve um atrativo muito especial para mim. A Sudene, na época, era o principal assunto da imprensa nacional. Tanto no Rio de Janeiro como em São Paulo as manchetes dos principais diários, e os editoriais dedicavam grande espaço para a criação da Sudene, em função, sobretudo, da repetição em 1958 de uma nova grande seca aqui do Nordeste. Tinha havido em 1951 e também foi, digamos, um evento muito negativo para a economia regional, e [isso] motivou o então governo de Getúlio Vargas a criar o Banco do Nordeste, em 1952. A assessoria especial do presidente da República, de Getúlio Vargas, era constituída por nordestinos ${ }^{4}$.

3 O economista Ragnar Nurkse (1907-1959), nascido na Estônia, destacou-se nas áreas de economia internacional, finanças internacionais e desenvolvimento econômico. Formou-se nas Universidades de Tartu (Estônia) e de Edimburgo (Reino Unido). Nesta última, obteve o grau em Economia, em 1932. Trabalhou em Viena entre 1932 e 1934, onde publicou artigos e conheceu economistas da escola austríaca como Haberler, Mises, Hayek, Machlup, Morgenstern, entre outros. Trabalhou na Liga das Nações entre 1934 e 1945, onde esteve envolvido com diversas publicações do órgão, entre elas o anuário Monetary Review, a The Review of World Trade e World Economic Surveys. A partir de 1945, tornou-se professor da Universidade de Columbia (Nova Iorque). Em 1958 e 1959, foi estudar desenvolvimento econômico em Genebra, onde faleceu subitamente. A maioria de seus últimos trabalhos sobre os problemas do desenvolvimento econômico e o comércio internacional resultou das suas conferências nas cidades do Cairo, Istambul, Rio de Janeiro, Cingapura e Estocolmo, assim como seus cursos em Columbia In Memória do Desenvolvimento, ano 1, no 01, 2007.Ed. Centro Internacional Celso Furtado, p. 7.

4 O entrevistado se refere aos quatro economistas do núcleo da assessoria, Cleanto de Paiva Leite (1921-1992), nascido na cidade da Paraíba, atual João Pessoa-PB; Ignácio 
- O senhor falava daquele grupo que gerou a criação do Banco do Nordeste.

É, era uma assessoria especial do presidente da República, Getúlio Vargas, que era constituída por nordestinos, uma simples coincidência. Era liderada por Rômulo Almeida, economista baiano, e integrado, entre outros, por Jesus Soares Pereira, que depois ficou no IBGE por muito anos, por Cleantho de Paiva Leite, paraibano que foi depois diretor do BNDES e diretor do Banco Interamericano de Desenvolvimento, e Evaldo Correa Lima, piauiense que, foi também diretor do BNDES e depois foi gerente geral de operações do Banco Interamericano de Desenvolvimento. Esses nordestinos, naturalmente sensibilizados pelos problemas da região, sugeriram ao presidente da República a criação de um banco, que deveria ser um banco de desenvolvimento, parecido com o BNDES, com atuação nacional. Esse banco deveria ter uma atuação similar, mas restringida à área do Nordeste. Na prática, em 1954, o banco fugiu um pouco às suas finalidades. $\mathrm{O}$ primeiro presidente do banco foi exatamente o Rômulo Almeida, que foi quem praticamente fez a implantação do banco, organizou as equipes iniciais, e criou, na época, o Escritório Técnico do Nordeste, chamado ETENE, que deveria realizar estudos de base sobre a economia regional. Com a saída de Rômulo em 1954, o banco, de certa maneira, se desviou um pouco das suas finalidades sob a alegação de que antes de realizar a sua função como banco de desenvolvimento, teria que se capitalizar. E passou a atuar predominantemente como banco comercial.

de Mourão Rangel (1914-1994), nascido em Mirador-MA; Jesus Soares Pereira (19101974), nascido em Assaré-CE e Rômulo Almeida (1914-1988), nascido em Salvador-BA. In Os boêmios cívicos - A assessoria econômica-política de Vargas (1951-54) COSTA LIMA, Marcos (org.) 


\section{- O que era o Nordeste naquele momento da história?}

Vargas foi sucedido pelo Juscelino, e, como todos sabem, tinha como propósito promover um progresso do Brasil numa escala muito maior do que era conhecida até então. O lema dele era '5o anos em 5', como vocês conhecem. E ele começou a executar um grande programa de investimentos. Mas esses investimentos se concentraram praticamente na região centro-sul, e com isto a defasagem do nível de desenvolvimento entre o Nordeste e o centro-sul se acentuou. $\mathrm{O}$ Nordeste tinha praticamente $30 \%$ da população brasileira e respondia por pouco mais de $13 \%$ da renda brasileira. Com a seca de 1958 , voltou a repetir-se o recurso aos métodos tradicionais de combate à seca, que, na realidade, se revelaram totalmente inadequados: consistiam, praticamente, em deslocar para as frentes de emergência destinadas às obras públicas grandes contingentes de agricultores do Semiárido, que se dedicavam a uma lavoura de subsistência, e que, com a seca, praticamente ficaram impossibilitadas de cultivar. Essa grande massa de trabalhadores não era assalariada; trabalhava sob regime de meação, ou seja, a sua remuneração consistia em ter direito a 50\% da safra de algodão, que era cultivada na grande propriedade, e a ter direito a cultivar numa pequena parcela de terra alimentos destinados às necessidades básicas da sua família. Quando vinha a grande seca essa produção de alimentos praticamente se tornava inviável, e toda essa massa de trabalhadores ficava sem ter o que comer. Então, a solução encontrada era criar alguma renda monetária para esses trabalhadores, contratando-os para a realização das obras chamadas de emergência. Isso já vinha desde o século XIX, quando houve a primeira grande seca crônica, a de 1877 , que motivou, inclusive, uma visita do imperador Dom Pedro II ao Nordeste, onde ele lançou a ideia do desvio das águas do Rio São Francisco, que só recentemente começa e se concretizar. Então, a repetição ao longo de várias décadas a mesma forma de tentativa de fazer face a um fenômeno climático que se repetia a cada 7,8 anos, se revelou inadequada, realmente, como uma forma, no meu ver, algum tipo, eu não digo de desenvolvimento, mas até de impedir uma deterioração da economia das zonas atingidas pela seca.

\section{- Na verdade, reforço dos mecanismos de dominação...}

Na realidade, as frentes de emergência atuavam como um reforço das estruturas de propriedades existentes, porque as obras que eram 
contratadas pelo governo federal e eram influenciadas por políticos, que eram grandes proprietários rurais. Com isso, o dinheiro federal, digamos, atingia um objetivo imediato de mitigar a fome daquelas populações privadas de maneiras de subsistência, mas em nada contribuíam para mudar a face da região ao não criar meios para que ela pudesse resistir de uma forma menos negativa ao fenômeno das secas periódicas. É aí que no final de 1958, gera-se no Nordeste um novo movimento, com a eleição dos prefeitos das capitais e dos governadores, nesse ano, pleiteando uma reformulação da estratégia do governo federal para o Nordeste. Foi o tema principal das campanhas políticas dos estados do Nordeste. E a oposição ganhou em vários deles: ganhou em Pernambuco, com Ciro Sampaio, ganhou na Bahia com Juraci Magalhães, ganhou no Rio Grande do Norte com Aluísio Alves. E curiosamente esses governadores, apesar de serem de oposição, se revelaram depois muito úteis para a realização do projeto da Sudene, porque os grupos políticos da região do Semiárido tinham uma forte representação no Congresso Nacional. E essa representação no Congresso Nacional evidentemente tinha uma grande influência na alocação de recursos federais para a região. Então, a definição das obras se fazia em função do prestígio dos deputados e senadores junto a diversos Ministérios, o que contribuía evidentemente para consolidar as estruturas existentes.

- É nesse contexto, então, que surge a Sudene?

É, em função do crescimento da repercussão do problema do Nordeste Juscelino convocou uma reunião de nordestinos no Palácio Rio Negro, em Petrópolis - o palácio de verão do presidente da República, para a qual Celso Furtado foi convidado. Ele tinha recém chegado de Cambridge, na Inglaterra, onde escreveu o seu famoso livro 'Formação Econômica do Brasil', e sido nomeado diretor do BNDES, com a função de se dedicar aos problemas do Nordeste. O Banco do Nordeste, que tinha criado o GTDN, o Grupo de Estudos para o Desenvolvimento do Nordeste, tinha acumulado uma grande quantidade de informações estatísticas, depois de três ou quatro anos de pesquisas na região. Mas essa quantidade grande de dados estava sem tratamento analítico. E isso foi feito por Celso Furtado, designado interventor no GTDN, que era dirigido por um outro nordestino, um homem com bastante conhecimento da região, mas sem informações especializadas. Era advogado do Banco do Brasil e, depois, 
foi senador pela Paraíba, Aluísio Campos. Celso, então, redigiu o famoso documento do GTDN, depois publicado como "Uma Política para o Desenvolvimento do Nordeste'. Esse documento, praticamente, lançava as ideias básicas que vieram a presidir a fundação da Sudene. Ou seja, a estratégia da Sudene já estava definida no documento. Essa estratégia consistia basicamente em três pontos, de uma forma muito resumida: a modificação da estrutura agrária da zona semiárida através de projetos de irrigação que fossem capazes de elevar a produtividade da agricultura

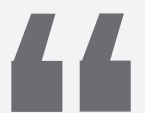

A realização de uma mudança na estrutura agrária na zona semiárida provavelmente levaria a uma liberação de mão de obra, haveria um excedente de população em relação à capacidade de suprimento da região semiárida. Por isso se pensou em deslocar parte dessa população para projetos de colonização nos vários úmidos do Maranhão, que naquela época ainda estavam muito pouco povoados.

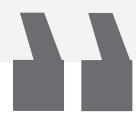
do Semiárido, essa era a primeira frente de ação. A segunda frente de ação era algo similar para a zona úmida, que era ocupada com o cultivo da cana. Aí, também através de projetos de irrigação, seria possível liberar terras para o cultivo de alimentos necessários para fazer frente a grande demanda que já existia nas zonas urbanas do norte e Nordeste, e, em consequência, a precificação do processo de urbanização. A realização de uma mudança na estrutura agrária na zona semiárida provavelmente levaria a liberação de mão de obra, haveria um excedente de população em relação à capacidade de suprimento da região semiárida. Por isso se pensou em deslocar parte dessa população para projetos de colonização nos vários úmidos do Maranhão, que, naquela época, ainda estavam muito pouco povoados. Posteriormente, esses vales úmidos, por incrível que pareça, passaram a ser ocupados, predominantemente, não por nordestino, mas por colonos que vinham do Paraná e do Rio Grande do Sul. E aí, num movimento espontâneo e não num movimento dirigido, como era o que pretendia a Sudene. O terceiro eixo de ação seria a industrialização da região através de projetos que se dedicassem, prioritariamente, ao aproveitamento de matérias primas regionais. Para isso o Projeto de Lei da Sudene previa a criação de incentivos fiscais que deveriam compensar a desvantagem relativa do Nordeste em relação ao centro-sul, como atração de projetos industriais. O centro-sul já dispunha de uma infraestrutura muito melhor do que a do 
Nordeste naquela época, gerando economias externas que possibilitariam reduzir o custo dos investimentos. Na época, era muito difícil conseguir a implantação de novos projetos industriais no Nordeste se não houvesse alguma compensação para o investidor. Essa compensação foi pensada através de incentivos fiscais, que se concentravam na isenção do imposto de importação e na destinação aos investimentos industriais de 50\% dos chamados 'fundos dos ágios', gerado pela venda de divisas estrangeiras destinadas a importação de produtos não essenciais para a economia regional. A política cambial brasileira tinha cinco categorias de dólar, que eram vendidos a preços diferentes em função do grau de essencialidade do produto. E começava desde 18,50 cruzeiros, que era a taxa mais baixa, e poderia atingir 70, 8o. Se falou de ágios... Isso se transformou numa das principais fontes de recursos do governo federal. Ele tinha uma arrecadação superior a do imposto de renda na época. Então, um dos ativos da Sudene destinava $50 \%$ dos fundos de ágios gerados pelas exportações do Nordeste ao financiamento de projetos industriais na região. Além disso, previa que $50 \%$ do imposto de renda das empresas localizadas fora da região também pudessem ser destinados a investimentos aqui no Nordeste. Todos esses investimentos teriam que passar pelo crivo da Sudene. A estratégia de industrialização teria nos incentivos fiscais, digamos, um dos seus pontos fundamentais. Esse tipo de incentivo viria a se modificar ao longo do tempo, porque, com o término do governo Juscelino, houve uma reforma cambial no governo Jânio Quadros em que foram extintas essas categorias de câmbio, e implantou-se um sistema de câmbio único, com o que o fundo dos ágios praticamente desapareceu.

- Então veja só, quando a Sudene foi criada, ao final de 59, correto? O primeiro Plano Diretor dela só foi aprovado no final de 61. Nesse período, como ficaram os recursos para a Sudene? Como ela funcionou?

Bom, em 1959, num primeiro momento em que se enviou o Projeto de Lei ao Congresso, foi criado por Decreto do Executivo, o Conselho de Desenvolvimento do Nordeste, com as mesmas atribuições da Sudene, praticamente, e sem recursos orçamentários. Esses recursos orçamentários só vieram a ficar disponíveis em 1962, com a aprovação do plano em dezembro de 1961. Mas eram recursos limitados. Nesse período a Sudene se manteve com recursos resultantes de 
um empréstimo do BNDES, que deveria ser quitado quando fosse aprovado o Projeto de Lei da Sudene. Mas eram atividades muito limitadas. Evidentemente, esses recursos foram utilizados praticamente para a implantação da sede da Sudene, em alguns andares alugados, e aquisição de móveis, etc. Na Sudene, os funcionários eram requisitados de outros órgãos do governo, e obtinham uma remuneração adicional na ordem de 30\% do seu salário base, que seria pago com recurso desse empréstimo do BNDES. Mas eram muito poucos na época, menos de 20 funcionários, incluindo o superintendente. Essa foi a equipe que funcionou nos primeiros meses.

\section{- O senhor já estava lá?}

Já. Estava o Celso como superintendente, dois ou três assessores, dentre eles o Mário Magalhães, que era funcionário do Ministério da Saúde; o Jorge Furtado, que era funcionário do Ministério da Fazenda; e o Chico Oliveira, que chegou um pouquinho depois. Nessa época ele [Chico] estava em São Paulo, numa empresa privada, mas era funcionário do Banco do Nordeste, e foi requisitado ao Banco. Posteriormente, chega o Juarez Farias, nos primeiros meses de 59, maio, junho, por aí; Jader Andrade, que ia dirigir o Departamento de Agricultura; e Estevam Strauss, que era da Universidade Federal, para dirigir o Departamento de Recursos Minerais. Foi uma época em que a Sudene também teve um bom aporte de recursos externos através de missões de assistência técnica, que vieram realizar alguns estudos básicos, que se revelariam importantes para as atividades posteriores de investimentos na região. Eram missões que vinham estudar problemas de solo na zona semiárida [para] projetos de irrigação. Havia missões do governo francês, missões do governo de Israel, missão do Fundo Especial das Nações Unidas ${ }^{5}$, missão do governo do Japão para projetos de comercialização de gêneros alimentícios e de implantação de centrais de abastecimento. Enfim, havia umas seis ou sete missões de assistência técnica de governos, de organismos internacionais e de governos estrangeiros aqui para a cidade. A aprovação do Plano Diretor foi outra batalha, porque ainda ao tempo do Codeno existia um projeto que era considerado básico para o desenvolvimento das

5 Foi concedido um empréstimo de 974 mil dólares para explorar as potencialidades de irrigação no segmento médio do Rio São Francisco. In A fantasia desfeita, Celso Furtado. In: Furtado, Celso Obra autobiográfica. Ed. Companhia das Letras, São Paulo p. 255. 
atividades da Sudene no período posterior: era o Projeto de Lei de Irrigação, que determinava a desapropriação por utilidade pública pelo menos de parte das terras que fossem beneficiadas com investimentos federais. O governo ao longo de setenta, oitenta anos de atuação contra as secas, havia conseguido acumular uma reserva de água na região semiárida, na ordem, se não estou equivocado, de 150 milhões de metros cúbicos, dos quais se aproveitavam apenas 5 milhões, pouco mais de $3 \%$ para projetos de irrigação. Então, havia um desperdício enorme de recursos. O recurso mais escasso na zona semiárida era exatamente a água, totalmente subaproveitada, depois de haver consumido muitos recursos do governo federal ao longo de décadas. A Lei de Irrigação se destinava, exatamente, a corrigir esse erro histórico, ao determinar que parte das terras beneficiadas com esses investimentos em açudagem fosse desapropriada para ser redistribuída e dedicada à produção de alimentos.

\section{- Um projeto interessante, mas tinha apoio político?}

Esse propósito [de aprovação da Lei de Irrigação] foi frustrado no Congresso porque as bancadas nordestinas, que obedeciam, evidentemente, aos interesses os grandes proprietários de terra na zona semiárida, foram os principais entraves a aprovação no Congresso Nacional. E o projeto terminou sendo arquivado por não ter sido aprovado na legislatura, como determina o Regimento Interno da Câmara dos Deputados. Quando um projeto não é aprovado em uma determinada legislatura ele não passa à legislatura seguinte, é arquivado. Para ser novamente apreciado ele teria que ser reapresentado. Bom, esse projeto chegou a ser aprovado na reunião do Conselho Deliberativo da Sudene realizada em Teresina, e com um voto que se revelou decisivo, ainda que possa ser surpreendente, o voto do representante das Forças Armadas no Conselho, que era o coronel Afonso de Albuquerque Lima ${ }^{6}$, que depois no governo Quadros foi nome-

6 "A representação das Forças Armadas tomou conhecimento do anteprojeto de lei de Irrigação do Nordeste, que tem por objetivo principal regular o uso da terra e da água, nas áreas de irrigação do Nordeste. Cabe-me inicialmente após o estudos detalhados- do assunto em apreço dar todo o apoio no sentido de aprovar essa Lei, que procura de modo justo e humano. Estabelecer as bases para o arrendamento da terra, principalmente quando beneficiada por obras públicas e irrigação. Com essa corajosa e oportuna iniciativa, dá-se o primeiro passo para criar verdadeiramente a base agrícola indispensável à expansão industrial que se pretende levar a cabo no Nordeste e, até o presente momento, deixada inexplicavelmente de ser levado em 
ado diretor geral do DNOCS. Isso, vamos dizer, tem uma influência muito grande no voto dos governadores, o voto do representante das Forças Armadas. Mas apesar de aprovado pelo Conselho Deliberativo com o voto dos governadores isso não garantia, como de fato não garantiu, a sua aprovação no Congresso Nacional. O primeiro Plano Diretor levou quase dois anos para ser aprovado. E antes de ser aprovado, teve uma tentativa de desfiguração do projeto no Congresso com uma Emenda Parlamentar que separava o DNOCS da Sudene.

\section{- Qual era a composição do Conselho Deliberativo da Sudene? Como ele funcionava?}

No Conselho Deliberativo da Sudene estavam representados todos os órgãos federais com atuação no Nordeste: o Departamento Nacional Contra as Secas, a Comissão do Vale do São Francisco, a Sudene, vários Ministério Federais, inicialmente eram sete, e depois se acrescentou a Companhia Hidrelétrica do São Francisco, ou seja, havia a maioria de órgãos do governo federal, mais os governadores dos nove estados. Depois se acrescentou Minas Gerais e Espírito Santo. Isso representou, na época, uma reforma administrativa de grande vulto porque era a primeira vez que um grupo de govenadores, vamos dizer, se reunia de uma forma orgânica em um colegiado para discutir, em conjunto, os problemas da região. Até então cada governador atuava individualmente defendendo o interesse de seu estado e evidentemente isso contribuía para reforçar o poder de pressão dos governadores quando se tratasse de um projeto de interesse regional. Isso não eliminava o interesse de cada governador por projetos estaduais. Isso vai se ver no desenrolar das reuniões do Conselho Deliberativo da Sudene, ou seja, de interesse bem documentado, onde vez por outra acontecia de um governador encaminhar um determinado projeto que poderia não merecer a aprovação do conjunto por defender um interesse

consideração. Esta Lei, há de sofrer contestações e talvez mesmo forte oposição, porque virá modificar, em parte, os alicerces econômicos da região nordestina e, sobretudo, porque virá atingir a uma poderosa classe de grandes proprietários de terras. Entretanto, pelo modo correto e equânime como está redigida e pelos nomes dos homens que participaram de sua elaboração, temos a certeza de poder aprova-la, com a convicção de que estamos praticando um ato de grande significação para o interesse do Nordeste, em particular, e da própria Nação”. In Ata da segunda sessão da terceira reunião extraordinária do Conselho Deliberativo do Conselho de Desenvolvimento do Nordeste, realizada no dia cinco de agosto de 1959, na cidade de Teresina. http://procondel.sudene.gov.br/acervo/ATA_E_S2_003_1959.pdf 
que poderia ser legítimo, mas não era um interesse regional; era um interesse exclusivamente estadual. Quando esse interesse não era atendido, evidentemente, isso gerava protestos do governador, críticas do governador ao enfoque regional, acusado de ser centralizador, enfim, de estar interferindo na autonomia dos estados, e isso era uma coisa recorrente. Era necessário, realmente, ter uma posição firme para que o ponto de vista regional viesse a se sobrepor ao ponto de vista de cada estado individualmente?

\section{- Então, o senhor ficou pouco tempo aqui [no Recife]?}

Fiquei quase dois anos. Em 1960 fui para o Rio e, do Rio, eu fui fazer a minha pós-graduação na Europa. Só regressei para o Brasil em 1962. Aí o Celso me pediu que eu voltasse para o Recife para implantar a assessoria técnica da Sudene aqui. A Sudene tinha crescido muito em atividade-fim e necessitava melhorar o seu nível de coordenação nas diversas equipes. Tinha crescido muito, tinha quadriplicado o número de funcionários, ou quintuplicado, de maneira que a assessoria técnica existia no papel, mas não existia de fato. Ela foi implantada praticamente com o meu regresso ao Recife. Não, digamos, em função da minha pessoa, mas porque o Celso me pediu para que viesse. Se não fosse eu, outra pessoa teria se encarregado dessa função. Eu voltei ao Nordeste, então, e aqui permaneci até $1^{\circ}$ de abril de 1964, quando se deu o golpe militar, depois de um longo processo de deterioração do ambiente político brasileiro, entre o fim de 1963 e o primeiro trimestre de 1964. Em 1962 a Sudene, já contando com recursos do Plano Diretor, passou a exercer um papel muito mais ativo na economia regional através do seu programa de investimentos. Foram investimentos em estradas, investimento em energia elétrica. Naquela época, só existia a primeira Usina de Paulo Afonso; hoje são quatro além de Moxotó, de Itaparica, Xingó e tem uma outra importante, não estou lembrado agora.

7 Criava-se um complexo sistema de contrapesos. Por um lado cada governador controlava os demais para que a repartição dos recursos não o prejudicasse... Meu propósito era fortalecer os governadores, expressão mais legítima da vontade popular em cada estado. E, ao mesmo tempo, introduzir o espírito regional em todos os debates e libertar a aplicação dos recursos federais da politicagem local. In: Furtado, Celso Obra autobiográfica. Ed. Companhia das Letras, São Paulo p. 244 A Fantasia desfeita. 


\section{- Sobradinho ?...}

Sobradinho. Naquela época existia a primeira Usina de Paulo Afonso. Cidades como Fortaleza, Teresina, não recebiam energia de Paulo Afonso, para isso, inclusive, a Sudene promoveu a criação da Usina de Boa Esperança, que deveria atender ao Piauí e ao Maranhão. Isso foi basicamente com recuso da Sudene, além do estímulo à extensão das linhas de transmissão da Chesf para atingir Ceará, Piauí e Maranhão. As condições eram inteiramente diferentes das que existem hoje. Era, de certa maneira, uma ação desbravadora, as estradas eram precárias, a energia elétrica era escassa, a educação superior era mínima. A gente teve que instituir um programa de bolsa de Agronomia, por exemplo, porque - isso está no livro do Celso - existiam, no primeiro ano, no curso de Agronomia aqui da Universidade Rural de Pernambuco apenas dez alunos, num estado carente de agrônomos, como era toda a região. A Geologia praticamente era uma especialidade que não existia aqui. A Sudene criou um programa de bolsas também na área de Geologia.

\section{- A gente estava falando da industrialização, das estradas, da eletrificação...}

Estou falando do novo, digamos, da realidade atual do Nordeste. Mas nós teremos que falar um pouco dos anos de 1962 e 1963. A aprovação do primeiro Plano Diretor foi outra grande batalha. Como eu dizia antes, houve tentativa de desfiguração. A mesma bancada que havia tentado obstaculizar a criação da Sudene, e criada a Sudene, tentou inviabilizar a permanência do Celso Furtado na Superintendência, esse mesmo grupo de políticos, quando se tratou de apreciar o projeto do Plano Diretor que estava no Congresso, tratou de reforçar as estruturas anteriores à Sudene, no caso o Departamento Nacional de Obras contra as Secas. E ele recuperava a sua autonomia e passava a contar também com Conselho Deliberativo similar ao da Sudene. Foi nesse momento que o Celso Furtado declarou que não permaneceria como superintendente caso essa Emenda fosse aprovada. Isso determinou, inclusive, um nocaute aqui em Pernambuco, que contou com o apoio do governador na época: em apoio ao projeto original do Plano Diretor da Sudene, o comércio de Recife fechou. Então, se uniram tanto as confederações patronais como as confederações sindicais, as confederações de trabalhadores. Foi um fenômeno politicamente novo, onde toda uma cidade paralisou as suas atividades 
em apoio a um plano de desenvolvimento. Isso nunca tinha ocorrido antes na história de Pernambuco.

\section{- Isso foi em 1961? E como ficou a Sudene após aprovação do Plano Diretor?}

É, segundo semestre de 1961. Aprovado o Plano Diretor, mantendo as suas linhas gerais, que tinha sido elaborada pela Sudene, já estávamos aí sob um novo governo federal, que era o governo de Jânio Quadros. Isso determinou umas modificações básicas, como eu digo, em consequência da mudança da política cambial, mas de toda maneira, com a aprovação do Plano a Sudene passou a contar com mais recursos. E o novo governo, supreendentemente, manteve o Celso como superintendente e, mais do que isso, um superintendente com mais prestígio do que no governo anterior. Celso estava em viagem ao exterior quando o presidente assumiu, e quando voltou esperava apenas transmitir o cargo ao seu substituto eventual. Eu na época dirigia o escritório do Rio ${ }^{8}$. Estávamos todos com as gavetas arrumadas esperando a designação do novo superintendente, quando Jânio Quadros convocou o Celso à Brasília, e não apenas o manteve como superintendente como lhe deu o nível de ministro de Estado, determinando que ele estivesse presente a todas as reuniões de Ministério, e determinando, também, ao Gabinete Civil a nomeação de um oficial de gabinete indicado pelo superintendente da Sudene para centralizar na Casa Civil as postulações do Nordeste, encaminhadas pela Sudene. De maneira que o presidente que tinha sido eleito com o apoio das grandes multinacionais e dos polos mais representativos da opinião da direita brasileira deu ao Celso Furtado um apoio tão grande, ou até maior, do que ele tinha no governo Kubistchek. Isso foi uma surpresa geral, inclusive para o próprio Celso. Essa atitude do governo Jânio Quadros, de certa maneira, confirmava uma linha desconcertante que ele impôs no seu governo, realizando uma política econômica de caráter tradicional, digamos, alinhada com o Fundo Monetário.

8 A Sudene, com sede no Recife, tinha escritórios regionais em cada uma das capitais nordestinas, além de Montes Claros-MG e no Rio de Janeiro. 


\section{- E foi aí que Sudene se inseriu no contexto da "Guerra Fria"?}

O Brasil estava com necessidade de divisas externas para suas importações essenciais. E para realizar aportes externos esses organismos internacionais, tanto o Fundo Monetário quanto o Banco Mundial exigiam uma série de reformulações da política econômica, dentre as quais a principal era uma reforma da política cambial. Ou seja, a extinção das diversas categorias de câmbio, a instituição de um sistema de câmbio único, extinguindo uma das principais fontes de recursos do governo, que era o fundo dos ágios. Com isso, você teria que realizar uma reforma fiscal com a finalidade de identificar novos recursos para financiar os gastos federais. Bom, temos aí todo o ano de 1961. Em agosto houve a renúncia surpreendente de Jânio Quadros, logo depois da Conferência de Punta del Este, onde se lançou a Aliança para o Progresso. O ano de 1961 também marca, de certa maneira, um certo ápice na repercussão internacional da Sudene. O Nordeste, em função dos seus problemas de desenvolvimento, passou a se inserir no clima da chamada Guerra Fria, que se realizava então entre o Ocidente e o Oriente. Um polo representado pelos partidos socialistas, liderados pela União Soviética, e o outro polo liderado pelo governo dos Estados Unidos com o apoio de todos os países da chamada Europa Ocidental. Esse embate se refletia em todo mundo, e aqui no Nordeste tinha surgido com muita intensidade o fenômeno das Ligas Camponesas, que pleiteavam a reforma agrária radical na região. As Ligas Camponesas, evidentemente, eram apresentadas lá fora como um risco para a estabilidade brasileira. Na mesma época tinha havido a vitória da Revolução Cubana, e a definição de Fidel Castro por um programa socialista. Isso evidentemente aguçou a atenção dos Estados Unidos para a problemática do Nordeste. Possivelmente isso deve ter influenciado o convite do governo americano para uma visita de Celso Furtado a Washington. Essa visita se deu, não me recordo exatamente o mês, mas foi no primeiro semestre de 1961, e ele foi recebido com grande destaque em Washington, recebeu um tratamento que eu pessoalmente acho que só se dispensava a chefes de Estado. Ele foi recebido sem ser ministro. Só foi ministro no governo do João Goulart. Foi recebido pessoalmente pelo Kennedy, que dedicou a ele mais de uma hora do seu tempo. Não era nem conversa de sala, foi pelo jardim da Casa Branca. Há fotografias dos dois conversando, passeando no jardim. Isso determinou a constituição de uma missão de cerca de 40 técnicos 
do governo americano, que se deslocaram ao Nordeste dois meses depois, chefiados por um ex-embaixador. [A missão] visitou todos os estados do Nordeste para identificar projetos que pudessem vir a merecer o apoio dos chamados Sistemas Interamericanos.

\section{- E eles decidiram apoiar algum projeto?}

O Banco Interamericano de Desenvolvimento tinha sido fundado recentemente, no início dos anos 196o. O banco tinha o seu capital integralizado por uma contribuição de todos os estados membros da OEA, mas essa contribuição estava subscrita, mas não totalmente integralizada. E para iniciar as suas operações o banco contava com o chamado Fundo Fiduciário para o Progresso Social, que era constituído exclusivamente por recursos do governo dos Estados Unidos. Então, ainda que fosse aprovado um projeto enquadrado nesse fundo, e este tivesse o voto de todos os diretores do banco, o diretor norte -americano tinha o direito de veto, uma vez que os recursos eram exclusivos do governo americano, ainda que administrado pelo banco. A Sudene veio a ser o primeiro órgão, não só do governo brasileiro, mas de um país latino-americano, a merecer a aprovação de projetos do BID. Esses projetos foram aprovados na primeira Assembleia dos governadores do BID, que se realizou no Rio de Janeiro, no segundo semestre de 1961, e se destinavam praticamente a abastecimento de água potável de cinco capitais do Nordeste e Campina Grande, projetos de habitação popular e alguns estudos básicos. Essas eram as linhas básicas. Em agosto [de 1961] realiza-se em Punta del Leste a Conferência da OEA que se destinava a aprovar um grande programa de investimentos para a América Latina. E esse programa refletia de certa maneira um novo espírito que dominava o governo americano na primeira metade do governo Kennedy, que era de promover algumas reformas básicas na América Latina, de maneira a destravar o processo de desenvolvimento. Quem ler a Carta de Punta de Leste vai verificar que ainda existe a recomendação de uma reforma agrária, de uma reforma bancária, de maneira que deveriam ser encampadas posteriormente pelo governo brasileiro já na administração Goulart, chamada Reforma de Base. Boa parte dessas reformas estavam previstas na Carta de Punta de Leste, que deveria nortear a aplicação de recursos dos chamados Sistemas Interamericanos, em toda a América Latina. Com a substituição do Jânio Quadros pelo João Goulart, existe uma nova tentativa de substituição de Celso na Superintendência da 
Sudene, mas ele não só é mantido como é encarregado pelo presidente de elaborar um plano de desenvolvimento para o conjunto do país, chamado Plano Trienal, que veio a ser lançado em 1962.

- Aí [Celso Furtado] já estava como ministro, de qualquer jeito? É, ele foi nomeado ministro extraordinário, porque, nessa condição, ele poderia ser nomeado pelo presidente sem intervenção do Congresso. O presidente da República tem competência para criar Ministérios Extraordinários. Já Ministérios Permanentes têm que ser aprovados por Projeto de Lei, e a situação do presidente no Congresso não era uma situação folgada. Então ele apelou para esse recurso constitucional e criou um Ministério Extraordinário com a função de planejar os investimentos federais .

- A literatura recorre a isso, mas eu queria que o senhor que viveu de perto isso me dissesse: existiu conflito entre a Sudene e as missões americanas?

Isso passou a existir no segundo semestre de 1962. Ou melhor, mais precisamente, em 1963, com a agudização da inflação externa, a invasão da Baía dos Porcos, em Cuba. Ainda foi no governo Kennedy. O próprio governo americano passou a incluir duas correntes importantes. Uma liderada pelo Departamento de Estado que, vamos dizer, alimentava a chamada Guerra Fria. E a outra por um grupo de assessores de Kennedy, que eram originários das universidades americanas, que tinha, evidentemente, uma orientação diferente. A ida do Celso a Washington, eu diria ter resultado em uma sugestão dessa equipe de universitários que assessoravam o Kennedy. Evidentemente que o clima mudou, com o acirramento da Guerra Fria, sobretudo depois da tentativa de invasão de Cuba, que ainda foi no governo Kennedy. E depois houve a tentativa de instalação de uma base de foguetes soviéticos em Cuba. O mundo esteve quase a bordo de uma guerra. Se não tivesse havido o recuo de Khrushchev ${ }^{9}$ mandando retroceder o navio que transportava os equipamentos para instalação dessa base em Cuba, possivelmente... ninguém pode afirmar, mas o mundo caminhava para um conflito entre Rússia e Estados Unidos, e isso

9 Nikita Serguêievitch Khruschov (1984-1971) liderou a União Soviética como Secretário-geral do Partido Comunista da União Soviética (1953-1964) e como presidente do Conselho de Ministros (1958-1964). 
evidentemente influiria em rumos da política externa americana. O governo Goulart passou a ser visto por órgãos do governo americano como um governo de esquerda, apesar de Goulart ter sido convidado a visitar os Estados Unidos, falar no Congresso Americano, passou a ser um governo não confiável para o Departamento de Estado. E isso, evidentemente, se refletiu nas atividades externas, na chamada ajuda externa. E Celso Furtado passou a ser atacado pela imprensa de direita no Brasil como um homem de esquerda. Antes, quando esteve nos Estados Unidos, foi violentamente atacado pela imprensa de esquerda. Chegou a ser chamado de lacaio de Wall Street e acusado de estar negociando a venda do Nordeste aos americanos. Isso foi publicado no jornal que era dirigido pelas pessoas vinculadas ao antigo Partido Comunista, que se chamava 'O Semanário' e era um jornal alternativo. É, evidentemente que com o acirramento da Guerra Fria, resultante do embate entre União Soviética e Estados Unidos, isso se refletiria evidentemente em todo o programa de assistência externa do governo americano. Em Pernambuco isso se tornaria ainda mais patente com a eleição de um governador que tinha tido o apoio ostensivo das forças de esquerda, inclusive do partido Comunista, e que imprimiria a sua atuação no governo com um selo próprio. A ajuda externa passou, então, a adotar um crivo que refletia essa divisão de águas que existia na própria administração americana. Como ela era administrada boa parte pelo Departamento de Estado, e o Departamento de Estado era o órgão do governo americano que atuava em seu nome na condução da Guerra Fria, o governo americano tentou retirar ou atenuar a influência da Sudene na alocação desses investimentos. Como essa tentativa foi feita? Através de entendimentos diretos com os governadores. Então os técnicos [americanos] passavam a se entender basicamente com as administrações estaduais. E isso se reflete nas atas do Conselho Deliberativo, muito bem documentado naquele artigo do Marcos 
Costa Lima. ${ }^{10}$ A Sudene não aceitou e isso se tornou muito patente num projeto de apoio a rodovias estaduais em Pernambuco.

\section{- Quer dizer, a Sudene não se submeteu...}

No livro 'A Fantasia Desfeita', Celso se refere expressamente a esse início de divórcio que passou a existir entre a ajuda externa e o projeto da Sudene. Mas a Sudene não abdicou das suas prerrogativas, é necessário que se acentue isso, ou seja, o governo americano evidentemente era livre para alocar os seus recursos onde quisesse, mas não contava com o aval da Sudene para todos os projetos que fossem executados na região. Por exemplo, a Sudene, nesse caso das estradas do Nordeste, das estradas de Pernambuco, chegou a atuar, vamos dizer, de maneira ostensiva salientando porque negaram os recursos, apesar de estar no planejamento, a Recife [denunciando] o caráter discriminatório que passou a haver na ajuda externa em função do posicionamento político de cada governador. Isso se reflete nas reuniões do Conselho Deliberativo. Tudo isso teria um desfecho no final de 62, início de 63, quando Celso Furtado reassume a Superintendência da Sudene, que tinha ficado, durante o período que ele foi ministro de planejamento, com o superintendente substituto, Francisco Oliveira. Já em 1962 o Celso estava muito preocupado com a situação política internacional. Ele chegou a elaborar um documento que se destinava aos candidatos ao Congresso Nacional, que seriam eleitos ao final daquele ano, em que advertia para as disjuntivas a que se deparava a economia brasileira. E ele explicava que para ele havia dois valores básicos a serem preservados: a liberdade e o desenvolvimento. Ele se insurgia contra algumas tendências que advogavam, digamos, uma revolução, liderada pelos partidos de esquerda no Brasil, e citava o caso da União Soviética, onde tais objetivos de aceleração do desenvolvimento foram atingidos, mas a custo de um alto custo em termos de liberdade individual, os gulags $^{11}$ e todas as arbitrariedades cometidas no governo de Stalin. Ele rejeitava tanto a solução revolucionária como a manutenção do status

10 O entrevistado se refere ao artigo "O Conselho Deliberativo da Sudene (1958-1964) escrito em 2009, por Marcos Costa Lima, In: O Nordeste e a saga da Sudene. Arquivos Celso Furtado n. 3, Rio de Janeiro: d. Contraponto/Centro Internacional Celso Furtado, p. 223.265

11 Sistema de campos de trabalhos forçados para criminosos, presos políticos e qualquer cidadão em geral que se opusesse ao regime da União Soviética. 
quo. Esse documento foi apresentado aos principais líderes políticos da época, inclusive ao presidente da República. Foi apresentado ao Santiago Dantas, que tinha sido ministro das relações exteriores na primeira etapa do governo Jânio, e foi apresentado ao Jânio Quadros, que leu o documento e disse: "Celso, você sempre idealista". Mas o fato é que o documento não teve maior receptividade. Ou seja, os parlamentares, os candidatos de esquerda estavam muito motivados por uma possível, digamos, mudança de caráter revolucionário, e a direita querendo derrubar o governo. Essa polarização evidentemente não convinha, segundo o Celso, aos interesses nacionais. Objetivo dele com esse documento foi alertar as lideranças sobre essas alternativas, e tentar obter um compromisso mínimo, do que estava no Plano Trienal, com reformas estruturais, mas livremente negociadas no âmbito do Congresso Nacional, sem necessidade de golpe de Estado. Ele se refere que em uma reunião com o presidente da República ele leu o documento, mas não esboçou qualquer reação. Posteriormente em uma conversa informal o João Goulart disse para ele: "Celso, o Osvino ${ }^{12}$ leu aquele seu manifesto e achou que ele estava muito bom para um golpe”. Isso está no livro dele. O general

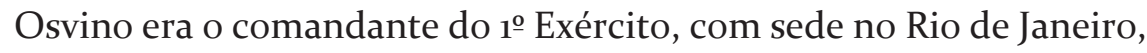
que foi logo descartado quando houve o golpe militar de 1964. Então, lamentavelmente ele não foi ouvido.

\section{- Qual o impacto que o senhor vê do golpe militar em relação ao desenvolvimento do Nordeste?}

Como não foi ouvido, Celso se recolheu aqui em Recife e, por essa época, eu já tinha vindo para cá. Passamos, então, a tentar, digamos, reorganizar um pouco a parte interna da Sudene, mas sem grandes ilusões quanto ao futuro. A predição dele praticamente se confirmou. O bloqueio das reformas de base no Congresso, o Jango recorrendo cada vez mais ao apoio de sindicatos e a setores das Forças Armadas, numa radicalização que preocupava as pessoas que iam um pouco mais adiante, mas que veio a redundar, evidentemente, no golpe de 1964. Esse golpe, Celso, surpreendentemente, foi incluído na primeira lista de cassados. Na mesma lista em que estavam Prestes, Goulart, Brizola, todas as lideranças de esquerda. Os dois primeiros

12 Osvino Ferreira Alves (1897-1981), general que comandou o 1ํㅡㄹ Exército de 1961 a 1964, destituído e preso, teve os direitos políticos cassados. 
presidentes militares, por coincidência, tinham sido comandantes do

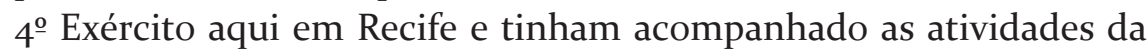
Sudene nos seus primeiros anos. Com o golpe militar, foi designado no dia o5 de abril um interventor na Sudene. Celso ainda permanecia em Recife. Esse interventor, coincidentemente, era um general que era funcionário da Sudene, funcionário da Companhia de Eletrificação Rural do Nordeste, um general reformado, Expedito Sampaio. Como ocorreu em todos os grandes órgãos federais, instaurou-se também um IPM na Sudene para tentar identificar os funcionários que tinham se definido mais como elementos de esquerda. Alguns deles foram afastados e outros chegaram a ser presos, incluindo o superintendente substituto, o Chico [Oliveira]. Foi preso na mesma noite em que jantou na minha casa com Celso Furtado, na noite do dia 05 de abril. Os meus pais residiam aqui...

- ... 53 anos depois...

É, exatamente, que coincidência! Eu tinha uma passagem comprada para ir ao Rio de Janeiro, no dia 02 de abril, entrevistar estatísticos que iam trabalhar aqui na assessoria técnica, mas considerei que já tinha havido o golpe, e viajar naquele dia implicaria fazer uma deserção. Mas eu não queria permanecer aqui. Eu fui o único diretor da Sudene que não esteve presente à transmissão de cargo, porque eu tinha ido, a pedido do Celso, visitar o interventor designado para entregar as chaves do prédio da Sudene e marcar a hora da transmissão do cargo para o outro dia. Para isso, eu tive que mobilizar o general Otaviano Marcos, que era o presidente da Companhia de Eletrificação Geral do Nordeste, a quem eu conhecia. Eu não conhecia o general Expedito, mas ele era cunhado do general Expedito. E eu fui com o general Otaviano Marcos entregar as chaves do prédio da Sudene e marcar a data e a hora da transmissão do cargo. Ele fez uma série de perguntas e me pediu para estar presente. Disse que queria conversar comigo logo após a transmissão do cargo. Mas eu não queria permanecer aqui, e não fui. Eu interpretei esse convite como uma tentativa de pedir que eu permanecesse, e a mim não interessava permanecer. Eu tinha voltado ao Recife praticamente por uma imposição do Celso e, digamos, eu queria retomar as minhas atividades no Rio. Mas tinha essa passagem. Era dia 02, e, por obrigação, permaneci em Recife até quando Celso permaneceu. Ele embarcou para Brasília na manhã do dia o6 [de abril] e eu embarquei para o Rio de Janeiro na tarde do 
mesmo dia. Levei [Celso] no meu carro ao aeroporto. O Diário de Pernambuco tinha publicado, dias antes, e eu referi isso na palestra lá na Fundação Joaquim Nabuco, um manifesto que tinha sido assinado por profissionais liberais aqui de Recife contra a intervenção federal em Pernambuco. Houve um momento em que se circulou muito a ideia de que Jango ia decretar a intervenção federal em dois estados, para cortar a cabeça de Carlos Lacerda no Rio de Janeiro, então estado da Guanabara, e seu principal adversário. Ou seja, um governo de esquerda e outro de direita. E aí os profissionais liberais aqui assinaram um manifesto contra a intervenção federal, e a minha assinatura estava lá. O Diário de Pernambuco depois do golpe, no dia 04 ou 05 de abril publicou: "recordando", e republicou esse manifesto, uma espécie de dedo duro para todo mundo. E o IPM da Sudene passou a chamar cada um dos que tinham subscrito aquele manifesto. No meu caso isso não me atingiu porque quando eu voltei ao Rio tratei de reassumir o Banco do Brasil, então eu já não pertencia à Sudene. Isso não me atingiu, mas muita gente foi chamada. Conta-se até um caso meio folclórico de um colega que assinou o manifesto, um jovem funcionário da Sudene e, justamente, filho do General Salvador Batista, que presidia o inquérito.

\section{- O filho do general?}

É, o filho do general que presidia o IPM. Então, um outro funcionário da Sudene foi convocado a depor lá no IPM, e o general perguntou para ele: "por que o senhor assinou esse manifesto?" Ele respondeu: "pelas mesmas razões que o seu filho assinou”. Saiu preso de lá.

- Doutor José Maria me diga uma coisa, o senhor disse que levou Celso até o aeroporto no seu carro e ele foi para Brasília. É.

- Tem um episódio, talvez o senhor se lembre disso, que parece que se ele fosse para o Rio ele certamente seria preso, então ele foi para Brasília... Não encontramos referências...

No Diário de Pernambuco, naquela época, já circulava a notícia da prisão iminente dele, e ele estava pronto para isso porque ele morava aqui no Primeiro Jardim... no Primeiro ou Segundo Jardim. Era um apartamento térreo. Eu nesses dias... Eu acho que eu era um pouquinho mais esperto do que os colegas, não dormi em casa nenhuma 
noite. Porque eles normalmente prendiam as pessoas à noite. $\mathrm{O} C$ hico foi preso à noite em casa, depois de ter jantado na minha casa. Então eu dormia fora. Morava na casa dos meus pais aqui. Desde o dia primeiro de abril, eu não dormi em casa nenhuma noite. Circulava a notícia de que ele [Celso Furtado] seria preso a qualquer momento, e ele já tinha uma maletinha pronta com as roupas para levar para a prisão. E algumas instruções, a quem procurar nesse caso. Celso tinha feito universidade no Rio de Janeiro, na época do Estado Novo, na ditadura de Getúlio Vargas. Na época do Estado Novo era repressão tanto à direita quanto à esquerda...Havia um inspetor que atuava na polícia do Rio de Janeiro e que tinha sido nomeado diretor do DOPS, e que fora encarregado da repressão durante a ditadura Vargas. E naquela época Celso era um estudante de Direito no Rio. Ele não se sentiu seguro de desembarcar diretamente no Rio, cassado, e visado pelo novo governo. Então optou por viajar à Brasília, onde ele tinha uma irmã que era funcionária do Senado, e deixar passar alguns dias antes de chegar ao Rio. E assim se fez. Nesse meio tempo ele recebeu a visita do então deputado paraibano pela UDN, que viria a ser governador da Paraíba, João Agripino. Não estou fazendo nenhuma inconfidência porque isso também está no livro dele, 'A Fantasia Desfeita'. Ele recebeu a visita de João Agripino, que era amigo dele desde os tempos de João Pessoa, na mesma faixa etária, e que foi visita-lo em Brasília, na casa da irmã dele.

\section{- Deputado da direita?}

Da direita. Era deputado pela UDN. Mas dá na mesma. Foi visitá-lo e Celso expôs a situação. João Agripino era amigo pessoal do general Ernesto Geisel, que era chefe do Gabinete Militar do... não sei se era o Ranieri Mazzilli ou se já era o Castelo Branco. Creio que ainda era o Ranieri Mazzilli, o presidente da Câmara que assumiu a Presidência na época, até se eleger o Castelo Branco pelo Congresso. O general Geisel telefonou para o chefe de polícia no Rio e pediu para que deixasse o Celso tranquilo. E ele desembarcou no Rio de Janeiro sem ser molestado e lá permaneceu ainda uns 20 dias, até embarcar para o Chile, para fazer um círculo de palestras lá no IPES - Instituto Panamericano de Planejamento Econômico e Social e de lá ele embarcou para os Estados Unidos, onde tinha convite de várias universidades americanas e optou para ir, inicialmente, para a Universidade de Yale. 
- Estamos chegando ao final da entrevista e não posso de deixar de fazer essa pergunta, que eu considero importantíssima: diante desse contexto que o senhor falou e viveu, qual seria o possível papel da Sudene hoje? O senhor acha que ainda cabe, para o desenvolvimento do Nordeste, uma instituição que pense o planejamento? Como o senhor avalia isso?

Uma instituição para o planejamento regional sempre tem um papel importante a desempenhar aqui no Nordeste. Um deles é o de reforçar os pleitos da região, conferindo uma dimensão regional a projetos que podem ter origem estadual, mas que também podem ter uma repercussão regional. Nesse sentido, um organismo de planejamento regional sempre será de utilidade. Agora, é evidente que as prioridades hoje teriam de ser diferentes daquelas que estiveram presentes no momento da fundação da Sudene. Talvez a única a ser mantida fosse a da utilização racional dos recursos hídricos, na zona semiárida, conferindo-lhe um caráter de permanência e não apenas emergencial, como tem ocorrido toda vez que tem uma grande seca aqui no Nordeste. Creio que essa dimensão ainda não foi atingida e caberia reforçá-la ainda hoje. Na zona úmida do Nordeste, evidentemente, também as coisas mudaram um pouco. Com a revalorização do preço do açúcar em relação ao que se tinha na época da Sudene, a zona dedicada ao monocultivo da cana, em lugar de ter sido reduzida como se propunha, foi ampliada. Dificilmente se conseguiria, hoje, reverter esse processo, sobretudo no âmbito do sistema democrático, porque todos esses setores têm representação no Congresso Nacional. Isso não implica dizer que essa estrutura é racional desde o ponto de vista dos objetivos da sociedade. Um monocultivo continua a ser um mono-cultivo, qualquer que seja o regime econômico. O rendimento da área cultivada no Nordeste ainda é bem inferior ao que se tem em São Paulo, o que indica a necessidade de se modernizarem os métodos de plantio da cana e de utilização das terras de melhor qualidade da zona úmida do Nordeste. Isso, talvez, devesse ser atualizado, mas a necessidade ainda se apresenta como um dos eixos a serem explorados em futuros projetos de desenvolvimento regional. O rendimento industrial do açúcar no Nordeste é equivalente ao que se tem em São Paulo hoje, mas o rendimento agrícola ainda é bem inferior. Portanto, isso indica a necessidade de maiores investimentos no sentido de melhorar o rendimento da área cultivada com cana. 
Obtendo-se um maior rendimento, evidentemente que isso significa uma maior quantidade de sacarose por hectare, poderia se liberar terra para o cultivo de alimentos, ajudando a baratear o preço dos gêneros alimentícios para população urbana da região. Ok? 